\title{
BMJ Open The art of being healthy: a qualitative study to develop a thematic framework for understanding the relationship between health and the arts
}

\author{
Christina R Davies, ${ }^{1}$ Matthew Knuiman, ${ }^{2}$ Peter Wright, ${ }^{3}$ Michael Rosenberg ${ }^{4}$
}

To cite: Davies CR, Knuiman $\mathrm{M}$, Wright $\mathrm{P}$, et al. The art of being healthy: a qualitative study to develop a thematic framework for understanding the relationship between health and the arts. BMJ Open 2014;4:e004790.

doi:10.1136/bmjopen-2014004790

- Prepublication history for this paper is available online. To view these files please visit the journal online (http://dx.doi.org/10.1136/ bmjopen-2014-004790).

Received 3 January 2014 Revised 19 March 2014 Accepted 3 April 2014

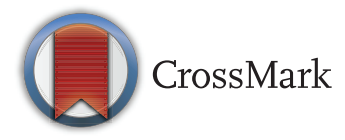

For numbered affiliations see end of article.

Correspondence to Dr Christina R Davies; christina.davies@westnet. com.au

\section{ABSTRACT}

Objective: In recent years the health-arts nexus has received increasing attention; however, the relationship is not well understood and the extent of possible positive, negative and unintended outcomes is unknown. Guided by the biopsychosocial model of health and theories of social epidemiology, the aim of this study was to develop a framework pertaining to the relationship between arts engagement and population health that included outcomes, confounders and effect modifiers. A health-arts framework is of value to researchers seeking to build the evidence base; health professionals interested in understanding the health-arts relationship, especially those who use social prescribing for health promotion or to complement treatments; in teaching medical, nursing and health-science students about arts outcomes, as well as artists and health professionals in the development of policy and programmes.

Design: A qualitative study was conducted. Semistructured interviews were analysed thematically. Setting: Western Australia.

Participants: 33 Western Australian adults (18+ years). Participants were randomly selected from a pool of general population nominees who engaged in the arts for enjoyment, entertainment or as a hobby (response rate $=100 \%$ ).

Results: A thematic analysis was conducted using QSR-NVivo10. The resulting framework contained seven outcome themes and 63 subthemes. Three themes specifically related to health, that is, mental, social and physical health, while economic, knowledge, art and identity outcomes were classified as health determinants. Within each theme, positive, negative and unintended outcomes (subthemes) were identified and categorised as relating to the individual and/or to the community. A list of confounding and/or effect modifying factors, related to both the arts and health, was identified.

Conclusions: Given the increasing pressure on health resources, the arts have the potential to assist in the promotion of health and healing. This framework expands on current knowledge, further defines the health-arts relationship and is a step towards the conceptualisation of a causal health-arts model.
Strengths and limitations of this study

- In recent years the health-arts nexus has received increasing attention from clinicians, researchers, health/social care professionals and policy-makers. However, evidence of the relationship between arts engagement and population health is in its infancy. Via a framework, outcomes need to be systematically identified and relationships scientifically demonstrated. ${ }^{3}$

- In this qualitative study, a framework to understand the relationship between arts engagement and population health was developed. The framework contained seven outcome themes: mental health, social health, physical health, economic, knowledge, art and identity outcomes. Within each theme, positive, negative and unintended outcomes of public and individual consequence were identified. The framework is of relevance to those interested in understanding the relationship between the arts and health, especially doctors and health/social care professionals involved in social prescribing for health promotion or in conjunction with conventional therapies and treatments.

- The strength of this study was that via a framework, a comprehensive account of the healtharts relationship was encapsulated in a clear, concise and user-friendly format. A second strength was that possible confounders and effect-modifiers to the health-arts relationship were identified and third, all participants invited to take part in an interview did so $(100 \%$ response rate). To reduce selection bias and increase sample credibility, interviewees were randomly selected from general population nominees who engaged in the arts for enjoyment, entertainment or as a hobby. The study was representative of the Western Australian population in terms of location and attendance of arts events, however, as nominees were initially recruited via purposive sampling, a limitation was that there was an over representation of females and people with a university or higher degree. 


\section{INTRODUCTION}

In 2002, the editor of the $B M J$ wrote 'Spend (slightly) less on health and more on the arts-health would probably be improved'. ${ }^{1}$ Smith's ${ }^{1}$ contention was based on the idea that diverting a small proportion of the British health budget to the arts could potentially improve the health of the general population, as true efficiencies to healthcare were likely to come from doing things differently, rather than quicker or at a lower cost. Evidence of the benefits of arts engagement has been mounting since the $1990 \mathrm{~s}^{2}$ However, the research has focused on specific groups (eg, patients, prisoners, youth) rather than the general population and on positive consequences rather than the variety of positive, negative and unintended outcomes. The research has also focused on art therapy or specific art programmes, rather than the art people do in their everyday lives for enjoyment, entertainment or as a hobby. In addition, the relationship between arts engagement and population health is largely unexplained, with a clear framework and scientific approach needed if we are to move the health and arts debate beyond anecdote and opinion. ${ }^{3}$ For researchers to establish whether or not a causal relationship exists between the arts and health the following needs to occur (1) a plausible conceptual framework of the relationship between arts engagement and health needs to be developed; (2) within this framework, possible confounders and effect modifiers to the health-arts relationship need to be identified (possibly via analogy from existing health-arts research or other research fields); (3) good study designs, that consider coherence and temporal order, need to be employed and (4) the strength, consistency, specificity and doseresponse relationship between arts engagement and health need to be considered. ${ }^{4}$ The development of a health-arts framework is a step towards the conceptualisation of a causal arts and health model and of value in (1) the design and analysis of research studies that seek to build the health-arts evidence base; (2) health settings that use social prescribing for health promotion, or to complement conventional medicine; (3) teaching students about the impact of the arts and (4) the development of health-arts policy and practice.

\section{Arts and health definitions}

It is suggested that arts engagement has both individual and community outcomes, ${ }^{5}$ as well as instrumental and intrinsic benefits. ${ }^{6}$ 'Arts engagement' can be defined as active (eg, making or creating art) or passive (eg, attending art events) involvement in creative events or activities within a variety of artforms (eg, performing arts, visual arts, literature). ${ }^{7}$ According to the WHO, 'health' is a resource for living via a state of physical, mental and social well-being and is more than the absence of disease or infirmity, ${ }^{8}$ while 'health determinants' involve the context of people's lives that influence health. ${ }^{9}$ An 'outcome' refers to the consequent effect of an action, programme, activity or event. ${ }^{10}$ In the health-arts context, confounders are factors relating to arts engagement that also affect health outcomes, while effectmodifiers are factors that make the effect of arts engagement on health smaller or larger.

\section{Arts engagement and health outcomes}

Clinical studies have found that arts engagement promotes relaxation and mental health by reducing patient stress, anxiety and depression. ${ }^{11}{ }^{12}$ For people experiencing mental health issues, arts programmes increase confidence, self-esteem and self-understanding. ${ }^{13}{ }^{14}$ In the general population, arts engagement improves psychological well-being and life satisfaction. ${ }^{15}{ }^{16}$ The arts also entail inclusive processes that act as a catalyst for creating connections between people who are similar (ie, bonding social capital) and people who are different (ie, bridging social capital) in terms of certain characteristics, for example, socioeconomic status, age. ${ }^{17}$ As a result, community arts programmes expand social networks and facilitate a sense of belonging. ${ }^{13}$ The arts have also been used in urban renewal projects to encourage community cohesion, identity and the development of civically valuable behaviours such as tolerance and respect. ${ }^{17-19}$ Research conducted in the UK, America and Sweden suggest that after controlling for a variety of factors, attending cultural events is positively associated with general health and longevity. ${ }^{20-22}$ With the exception of general health and longevity, few studies have looked at the direct physical health outcomes associated with arts engagement, for example, health behaviours. ${ }^{23}$ In addition to health, engagement in the arts has been found to impact health determinants such as learning and skill development ${ }^{6} 192425$ and enhances economic activity, by influencing the income of arts organisations and artists, as well as indirect spending in other areas of the economy (eg, transport, tourism). ${ }^{18} 19$

\section{Aim of this study}

The arts, with its emphasis on self-expression, creativity and understanding has a unique contribution to make to health ${ }^{26}$; however, the health-arts relationship, is not well understood and the extent of possible outcomes, not immediately obvious. As guided by theories of social epidemiology (eg, psychosocial, ecosocial $)^{27}$ and the biopsychosocial model of health, ${ }^{28}$ the aim of this qualitative study was to develop a framework pertaining to the relationship between arts engagement and population health by exploring the positive, negative and unintended outcomes gained by members of the general population and to identify possible confounders and effect modifiers.

\section{METHODS}

\section{Recruitment and sampling}

Purposive random sampling was utilised in this study. ${ }^{29}$ First, to encourage a range of people from the general 
population to nominate, the study was advertised via the email lists of two universities, two arts organisation and one health organisation. It was possible for people receiving the study email to on forward (snowball) the email to their friends, family and colleagues. Paper-based flyers were also posted on three arts-related community notice boards. The nomination criteria asked for (1) adults, aged 18 years or over who (2) engaged in the arts for enjoyment, entertainment or as a hobby. The art forms prompted in the email/flyer were the visual arts, craft, performing arts, literature, digital/electronic arts and community festivals. The modes of arts engagement prompted included making/ creating art and attending events. Purposive sampling is often used in qualitative research to gain access to people who are able to answer a specific research question due to predetermined criteria, such as their experiences, knowledge or specific characteristics, and leads to greater depth and richness of the data collected. ${ }^{29}$ Overall, 98 general population adults nominate for inclusion in the study via the telephone $(n=2)$ or by completing an online form $(n=96)$.

Second, to increase sample credibility $^{29}$ and reduce selection bias, of the 98 adults who nominated, 33 people were randomly selected for an interview using a random number generator in Microsoft Excel 2010 (ie, RANDBETWEEN[0,1] where 1 equals include). Although there are no established cannons of qualitative practice regarding sample size, the literature suggest that 20-30 interviews is sufficient to reach data saturation (ie, the point in a study where no new themes or concepts relevant to the research question are evident in the data). ${ }^{30}$ Of the 33 interviews conducted, data saturation was reached at 27 interviews, but to increase study quality and trustworthiness the extra six interviews $(20 \%)$ were conducted. All participants selected to take part in an interview did so (response rate=100\%). Table 1 shows the demographic profile of nominees and interviewees. Although, representativeness is not necessarily the goal of purposive random sampling, for comparison purposes, the demographic profile of the 2011 Western Australian population has also been included. ${ }^{31}$

\section{Data collection}

A semistructured interview guide was developed by the research team, ${ }^{32}$ reviewed by a panel of eight experts with experience in market research, the arts or public health and then piloted with two volunteers. The interview guide contained a mix of questions including, but not limited to, those shown in box 1. Question four (box 1) was phrased in the third person to allow participants to speak freely, especially about negative experiences or behaviours. The interviews took place between August 2010 and January 2011. All interviews were conducted by the first author (CD) at a time and place convenient to the participant. Handwritten notes were made at the end of each interview to record emergent thoughts and ideas. Interviews ran for approximately
$1 \mathrm{~h}$, were tape recorded and transcribed verbatim by an audio typist. All participants answered all interview questions. Transcripts were checked against the tape recordings for accuracy and errors by the researcher who conducted the interviews.

\section{Data analysis}

The qualitative software QSR-NVivo $10^{33}$ was used to manage, code and analyse the data. In qualitative research, computer packages such as QSR-NVivo 10, increase analysis transparency, accuracy, efficiency, rigour and trustworthiness. ${ }^{34}$ Using guidelines developed by Braun and Clarke, ${ }^{35}$ a thematic analysis was conducted to identify, analyse and report on patterns (ie, themes) within the interview data. Based on the literature, theoretical nodes were identified by CD and PW prior to coding. The 17 theoretical nodes that formed the starting point for the analysis were learning, identity, economic activity, income, mental health, relaxation, stress reduction, reduced anxiety/depression, confidence, self-esteem, self-understanding, self-expression, social capital, networks, support, physical health and life satisfaction. 16 11-25

Interview transcripts were read several times. Concepts relevant to the research question were coded into the existing theoretical nodes, or as new concepts emerged, coded into inductive nodes. By combining or separating nodes, potential themes and subthemes were created and defined by CD, PW, MK and MR, to establish themes and subthemes that were coherent, consistent and distinctive. As part of the analysis process, NVivo 'word frequency queries' were run to identify words and word groups (eg, stem words, synonyms) that occurred most often, as well as the relative and absolute frequency of word/word groups within the data set. ${ }^{36}$ To ensure the analysis was comprehensive in terms of data coverage, 'text search queries' were used to look for (1) specific themes and subthemes; (2) words with a shared stem (eg, health, healthy) and (3) words with related meanings (eg, healthy, well, fit). ${ }^{36}$ As guided by the literature, ${ }^{20-22} 3738$ reference to possible confounders and effect modifiers plausibly related to health and the arts were identified via a text search query. Via a 'matrix coding query', subthemes were identified as positive (Q4A), negative (Q4B) and unintended (Q4C). A matrix coding query enabled concepts to be crosstabulated across nodes and displayed in a row/column, table format. ${ }^{36}$ The resulting table allowed for data assessment and comparison. By 'clicking' within the table, qualitative transcript data corresponding to each cell of the matrix could be reviewed. ${ }^{36}$ Thematic maps (tree maps) and word clouds were modelled in NVivo to visually represent the relationships between themes and subthemes. Finally, themes were named, defined and then classified as either a 'health' or 'health determinant' outcome. On the basis of whether a subtheme was of private and/or public consequence, it was categorised as relating to the 'individual', 'community' or both 
Table 1 The demographic profile of the Western Australian population, study nominees and interviewees

\begin{tabular}{|c|c|c|c|}
\hline Demographic & $\begin{array}{l}2011 \text { Western Australian population } \\
\text { ( } \mathrm{N}=2.39 \text { million) (\%) }\end{array}$ & $\begin{array}{l}\text { Nominees }(n=98) \\
(\%)\end{array}$ & $\begin{array}{l}\text { Interviewees }(n=33) \\
(\%)\end{array}$ \\
\hline \multicolumn{4}{|l|}{ Gender } \\
\hline Male & 50 & 29 & 39 \\
\hline Female & 50 & 71 & 61 \\
\hline \multicolumn{4}{|l|}{ Location } \\
\hline Metropolitan & 78 & 78 & 79 \\
\hline Rural & 22 & 22 & 21 \\
\hline \multicolumn{4}{|l|}{ Education } \\
\hline High school or less & 51 & 16 & 15 \\
\hline Trade certificate or diploma & 7 & 18 & 9 \\
\hline University or post graduate degree & 14 & 65 & 76 \\
\hline Other or not stated & 28 & 0 & 0 \\
\hline \multicolumn{4}{|l|}{ Age group (years) } \\
\hline$\leq 19$ & 26 & 4 & 6 \\
\hline $20-29$ & 15 & 36 & 33 \\
\hline 30-39 & 14 & 13 & 16 \\
\hline $40-49$ & 15 & 13 & 12 \\
\hline $50-59$ & 13 & 21 & 21 \\
\hline $60+$ & 17 & 12 & 12 \\
\hline \multicolumn{4}{|l|}{ Art form ${ }^{\star}$} \\
\hline Visual arts, design and craft & $\dagger$ & 65 & 64 \\
\hline Performing arts & $\dagger$ & 67 & 58 \\
\hline Literature & $\dagger$ & 46 & 36 \\
\hline Electronic, online and digital arts & $\dagger$ & 19 & 15 \\
\hline Festivals and fairs & $\dagger$ & 55 & 45 \\
\hline \multicolumn{4}{|l|}{ Mode of engagement* } \\
\hline Make or create art & $\dagger$ & 72 & 79 \\
\hline Attend events & $\dagger$ & 88 & 88 \\
\hline Member of an arts organisation & $\dagger$ & 52 & 58 \\
\hline $\begin{array}{l}\text { Work or volunteer in the arts } \\
\text { (non-professional) }\end{array}$ & $\dagger$ & 37 & 33 \\
\hline $\begin{array}{l}\text { Completing an arts course (formal } \\
\text { or informal) }\end{array}$ & $\dagger$ & 26 & 21 \\
\hline
\end{tabular}

'individual and community'. Frequent meetings and discussions between CD, PW, MK and MR ensured thorough coding, agreement in the development of framework themes and subthemes, as well as the selection of appropriate transcript extracts.

\section{Ethics}

All nominees consented to inclusion in the study and granted permission for research staff to contact them via the telephone if they were randomly selected for an interview. All interviewees were provided with an information sheet that outlined the study purpose, confidentiality and data use. Participation in the study was voluntary, including the option to decline to answer questions or to stop the interview at any time. Informed consent (verbal and written) to participate and for interviews to be recorded was obtained from all interviewees. Participant data were deidentified during the transcription process.

\section{RESULTS}

The thematic analysis resulted in 850 individual coded-statements from which seven primary outcome themes were identified: mental health, social health, physical health, economic factors, knowledge, art and identity. Mental health outcomes (330 of 850 coded-statements) were mentioned seven times more frequently and social health outcomes (251 of 850 coded-statements) five times more frequently than other outcomes. Physical, mental and social factors were classified as 'health' outcomes, while art, economic, knowledge and identity factors were classified as 'health determinant' outcomes. Within each of the seven primary themes were both positive/negative and individual/community outcomes.

\section{Health outcomes}

Mental health

Mental health is the foundation for individual well-being and the effective functioning of a community. ${ }^{39}$ In this 


\section{Box 1 Interview questions and visual prompts}

1. Tell me about your most recent experience of engaging in the arts?

2. Tell me about the type of art you do the most?

3. If you were to describe to a friend or family member why you <attend $>/<$ participate $>$ in , what would you say?

4. I'd like to introduce you to two different people (show stick people card). Like you, $<$ Laura $>\mid<J o h n>$ (name matched to gender of the interviewee) $<$ attends $>/<$ participates $>$ in (activity matched to interviewee's activity), whereas <Jane $>/<\mathrm{Tim}>$ (name matched to gender of the interviewee) never $<$ attends $>/<$ participates $>$ in the arts.

A. How do you think arts engagement positively effects $\langle$ Laura's $>/<$ John's $>$ life?

B. How do you think arts engagement negatively effects $<$ Laura's $>/<$ John'S $>$ life?

C. Do you think $<$ Laura $>/<$ John $>$ would experience any unintended outcomes or consequences as a result of engaging in the arts? What would they be?

D. How do you think arts engagement makes $<$ Laura $>/<$ John $>$ feel?

E. If $<$ Jane $>\mid<$ Tim $>$ was to start engaging in the arts how would $<$ his $>\mid<$ her $>$ life change?

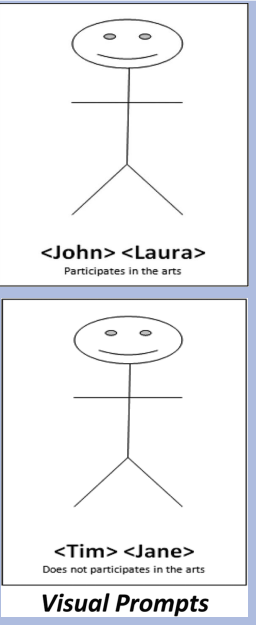

study 20 mental health subthemes were identified of which half were positive and most related to the individual (figure 1). Overall, arts engagement made people feel happy, was enjoyable, satisfying and resulted in the creation of good memories. Most study participants felt the arts made them more mentally resilient. Some participants felt the arts energised them, while others suggested it was relaxing and 'reduced their stress'. Arts engagement increased participant's self-efficacy (eg, confidence, self-esteem) and was a means of selfexpression and self-reflection. Participants liked that creating art sometimes resulted in compliments and recognition which in turn made them feel valued and respected, for example,

It encourages you to be yourself and be happy. It makes you a more confident person, especially if you are good at what you do and then you get compliments so you feel good about yourself. (Female, 20-29 years, Performing Arts)

On the negative side, arts engagement occasionally made participants feel marginalised for being 'arty' and sometimes led to undesirable emotions such as frustration, disappointment and anxiety.

\section{Social health}

Social health is influenced by the strength of a person's network, their understanding of intersubjective norms and capacity to make their own choices. Overall, 11 social subthemes were identified, of which all were positive (figure 1). Three-quarters of those interviewed suggested that the arts increased their network, as it was a way of meeting people of similar and diverse backgrounds, for example,

You build a network without even realising. You've got such a range of people who you would never in your normal life meet. They might only see each other once a week but, it's like you are the oldest friends because you have this really strong love of something that connects you. (Female, 40-49 years, Visual Arts)

Arts engagement reduced feelings of isolation, increased feelings of support and resulted in positive shared experiences. As the arts are a form of entertainment, it was a means of staying in touch with friends and family (eg, attending a concert together). Interviewees also obtained enjoyment from giving and receiving art. Through arts engagement, interviewees felt they were part of their community. They felt they were more community minded, that the arts gave them a wider appreciation of society and broadened their ideas/beliefs (eg, the arts helped them see other people's perspectives and made them question social norms and stereotypes). Overall, the arts made some study participants feel they were more 'interesting', 'worldly' and 'cultured'.

\section{Physical health}

Eight physical health subthemes were identified of which half were positive and most related to the individual (figure 1). Interviewees indicated their arts engagement resulted in physical activity such as walking, standing for long periods of time, warm-ups and performance-based movement such as dancing, for example,

I walk around looking for a good [photographic] shot.

Sometimes I've walked for an hour. (Male, 40-49 years,

Visual Arts)

On the negative side, participants also discussed how arts engagement could result in physical pain or injury (eg, discomfort from repetitive movements, hearing damage from loud concerts) and that particularly in the visual arts, some materials are poisonous (eg, solvents, glazes). As arts events are often at night, some participants experienced tiredness. It was also suggested that 


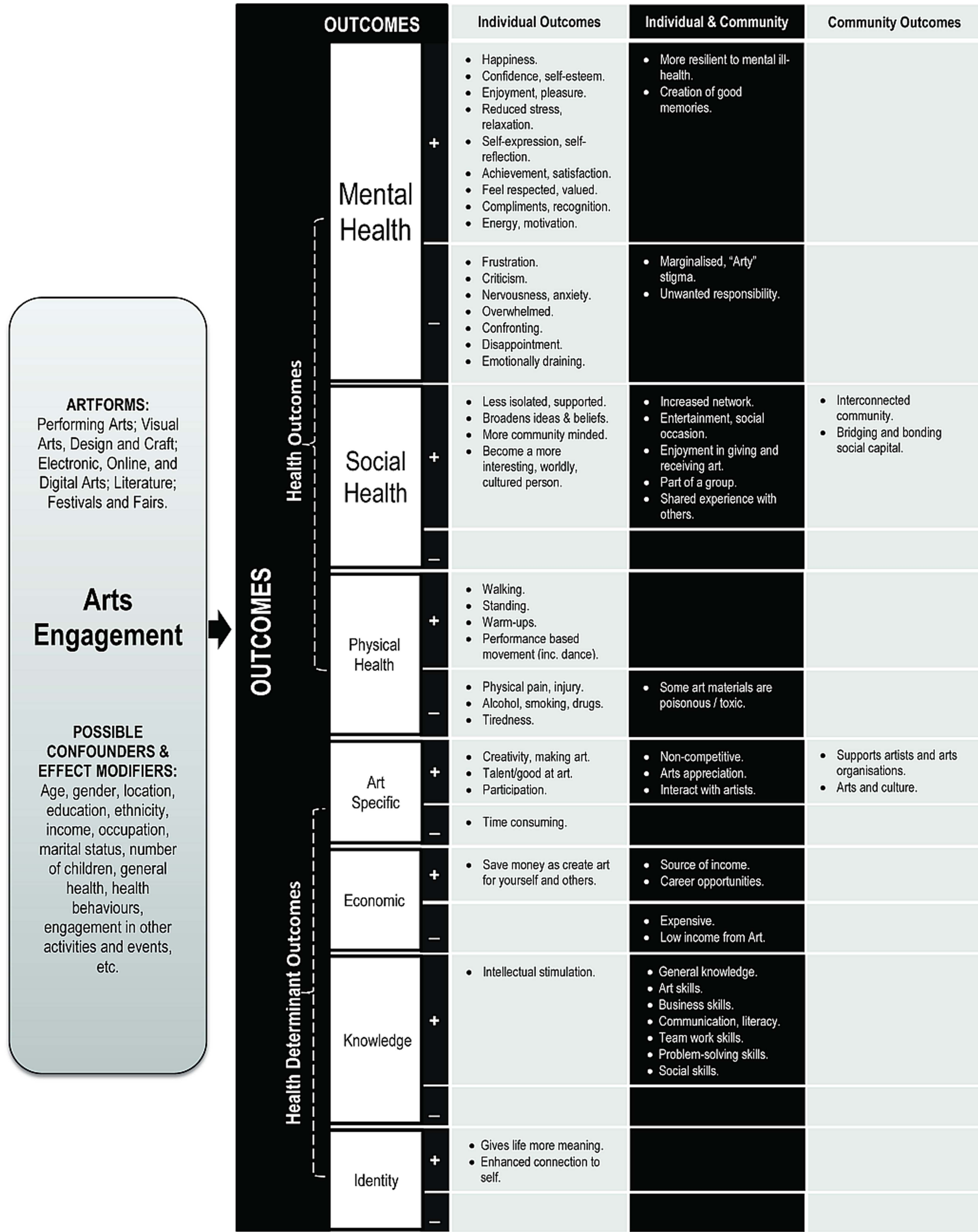

Figure 1 Arts and health framework. 
arts events could have negative health outcomes, as in some instances people drank too much alcohol, took drugs, smoked and breathed in second-hand smoke, for example,

There is a negative effect of being in the arts. You might not realise how much more you start drinking. (Male, 20-29 years, Performing Arts \& Literature)

\section{Health determinant outcomes \\ Art}

Art-specific outcomes occur via the expression and appreciation of the aesthetic through the process of making and/or experiencing art. In this study, nine art subthemes were identified, the majority of which were positive (figure 1). Overall, most participants thought they had a talent for art. They liked that the arts were non-competitive and allowed them to interact with and support artists and arts organisations. Interviewees also discussed the importance of arts participation, appreciation and creativity in their lives, but felt that arts engagement was very time consuming, for example,

It can be quite time consuming and you can lose track of things ...so, with a CD, you mean to sit there for five minutes in between other tasks and half an hour later you are still sitting there. (Female, 19 years or less, Festivals)

\section{Economic factors}

Economic factors are key determinants of health ${ }^{9}$ and relate to the resources available to a person. In this study, five economic subthemes were identified (figure 1), with most participants discussing how expensive arts engagement can be, for example,

It can be cost prohibitive and that's not just for the ticket. It could also be for the transport, babysitter, the cost of food. (Female, 20-29 years, Festivals)

The ability to create art gave participants potential career options and opportunities (eg, amateur exhibitions, travel). Performing or making art was seen as a potential source of income; however, participants felt the community was not willing to remunerate highly for amateur artworks and performances. Making art also allowed some interviewees to save money, as they could create artworks for themselves and others, for example,

There is a practical outcome for presents and for myself to put on the wall. You don't have to go to the shops. You can make it yourself. (Female, 20-29 years, Visual Arts)

\section{Knowledge}

Knowledge outcomes relate to the process of formal, informal or unintentional learning and are a key determinant of health. ${ }^{9}$ Overall, eight knowledge subthemes were identified, of which all were positive and most related to the individual and community (figure 1).
Study participants described the arts as intellectually stimulating. They discussed how the arts developed their capacities and capabilities, especially the development of general knowledge and skills (eg, art, business, team work, problem-solving, social, communication and literacy).

I guess there is a learning process ... It [art] expands your realms of knowledge, vocabulary and your spelling. (Male, 20-29 years, Literature)

\section{Identity}

Identity relates to how a person sees him or herself and how they are viewed by others. Identity is influenced by a person's characteristics, thoughts and beliefs. Overall, two identity subthemes were identified (figure 1). Both subthemes were positive, with interviewees indicating that the arts enhanced their connection to self and gave their life more meaning:

Who I am, is about who I am when I am doing my art. Art gives you something that is totally yours, beyond family, commitments, work. You have a greater understanding of yourself and your life...creating art gives you that chance to express meaning for yourself and life. (Female, 50-59 years, Electronic/Digital Art)

\section{Unintended outcomes}

Study participants were asked about the unintended outcomes resulting from engagement in the arts. Participants agreed that some outcomes were unintended, especially social outcomes, such as the ability of the arts to increase a person's network. Participants also mentioned that the development of business skills and arts related physical activity was unexpected. Other unintended outcomes included feelings of achievement, confidence, self-esteem, happiness, unexpected compliments and recognition. On the negative side, a few participants talked about injuries, increased alcohol consumption, smoking and tiredness being unintentional outcomes of arts engagement.

\section{Confounders and effect modifiers}

On one or more occasions, interviewees made reference to age, gender, location, ethnicity, education, income, occupation, marital status, children, general health, health behaviours and engagement in other events/ activities in relation to arts engagement or both arts engagement and health. Factors that emerged as particularly important were income, engagement in other activities (especially sport) and location.

\section{DISCUSSION}

The aim of this qualitative study was to develop a framework pertaining to the relationship between arts engagement (for enjoyment, entertainment or as a hobby) and population health that would be useful to doctors, researchers, teachers, health/social care professionals, 
policy-makers and artists. The findings of this study are represented in a conceptual framework (figure 1). Within the framework, three themes specifically related to health, these being mental, social and physical health, while art, economic, knowledge and identity outcomes, were classified as health determinants. Mental health and social health were shown in larger font (in the framework) as participants mentioned them more frequently than other outcomes. This could suggest that arts engagement had a greater impact on mental and social health than other outcomes; however, this assumption requires further investigation. As previously stated, for the health-arts field to ascertain whether or not a causal relationship exists between health and the arts, (1) a plausible health-arts framework needs to be developed and (2) health-arts confounders and effect modifiers need to be identified and accounted for when analysing data. Cross-sectional studies can be used for establishing associations, but to establish causality the field needs to move to randomised interventions and longitudinal studies. Our paper addresses the need for a framework and identifies possible health-arts confounders/effect modifiers. Factors shown in the framework may be both confounders and effect-modifiers, but this requires further investigation. Acknowledging the existence of confounders and effect-modifiers and accounting for them in future analyses, enhances our ability to avoid spurious conclusions about the health-arts relationship and assists us to more accurately quantify the magnitude of this relationship.

In this study we chose to focus on the general population, and the art they do in their everyday lives, rather than the more common practice of focusing on particular target groups or specific arts programmes, as it is our view that the arts can make a difference to the overall health of the community, not just specific subgroups. The significance of a population-based health-arts framework is that a population health approach to research and practice can now occur and be guided by this framework. This is not to say that the framework is only relevant to the general population. Many of the outcomes included in the framework are also found in the arts programme literature. ${ }^{40} 41$ Therefore, although members of the general population were interviewed we believe that the framework equally applies to demographic subgroups and should also be useful when evaluating the outcomes of arts programmes, but that the effect of arts engagement on specific mental health, social, physical, economic, knowledge, arts-specific and identity outcomes may vary (ie, be larger or smaller) for specific groups due to effect modification, a list for which is provided in the framework.

\section{Comparison with other studies}

The outcomes associated with arts engagement are interconnected, iterative, relational and temporally bound. ${ }^{40}$ As postulated by Iyengar $e t a l^{5}$ arts engagement was found to have a number of outcomes of individual and public consequence. In this study, the relationship between arts engagement and population health was also found to be a composite of positive and negative outcomes. Overall, interviewees more frequently mentioned individual rather than community outcomes, and positive rather than negative outcomes. Given the qualitative nature of this study, this is to be expected as memory about self-events is superior to other-events, and pleasant events recalled better than unpleasant. ${ }^{42}$ These findings are also interesting as they highlight the mismatch between why people participate in the arts (ie, mostly for subjective reasons) as compared to why the arts are valued and funded (ie, due to the benefits they provide to the community). ${ }^{6}$

In $2009-2010,86 \%$ of Australian adults and $88 \%$ of Western Australian adults attended at least one cultural event or venue in the previous 12 months. ${ }^{43}{ }^{44}$ Given the numerous positive outcomes associated with arts engagement found in this and other studies, it is not surprising that the arts are a popular pastime. Nonetheless, the identification of negative outcomes, such as excessive alcohol consumption and exposure to second-hand smoke may reduce some of these positive benefits. It is beyond the scope of this study to explore whether negative outcomes are caused by arts engagement, or are a reflection of those who engage in the arts. However, if arts events are places where negative health behaviours occur, then health organisations should sponsor the arts to encourage healthy environments and promote health to audiences and participants, that is, 'Health in Arts'. ${ }^{37}$ In Australia, health-arts sponsorship agreements to advocate physical activity, antismoking, sun protection, nutrition and safe alcohol consumption have been found to be effective. ${ }^{37} 3845$ In addition to negative health outcomes, study participants also acknowledged that some outcomes were unintended, particularly social benefits. This finding should be of interest to those conducting health-arts programme evaluations, as evaluations are often based on predetermined aims and objectives; however, this study suggests that arts outcomes can extend beyond what is anticipated or planned.

\section{Implications for clinical practice}

As the pressure on health systems, resources and providers grows, many are calling for a demedicalisation of people's lives and the search for more holistic solutions that encourage patient learning, autonomy and selfcare. ${ }^{46}$ The arts have the potential to become an important form of health promotion and healing, therefore, this study suggests four important points for clinicians and health/social care professionals. First, engagement in the arts has the potential to positively influence mental health, social health, physical activity and health determinants in the general population. Second, the framework increases understanding of the possible outcomes of social prescribing, especially Arts on Prescription. ${ }^{47}$ Third, arts-related outcomes can be both positive and negative and this should be considered when suggesting or prescribing creative events and activities. Finally, the 
majority of patients may not realise the potential impact of arts engagement for health promotion and/or recovery, therefore if the arts are prescribed to a patient, the framework could be used to explain and increase their understanding of arts-related outcomes.

\section{Strengths and limitations of the study}

Strengths of this study include the development of a succinct and comprehensive health-arts framework, including possible confounders and effect-modifiers. To reduce selection bias and increase sample credibility, interviewees were randomly selected from a pool of nominees. In addition, all participants invited to take part in an interview did so. Overall, nominees and interviewees reported similar levels of arts attendance $(88 \%)$ to those reported for the general population in 2009-2010 by the Western Australian Department of Culture and the Arts. ${ }^{44}$ The sample was also representative of the Western Australian population in terms of metropolitan or rural location, however, a limitation was that there was an over representation of women and people with a university or higher degree. This is likely the result of the purposive sampling technique employed to recruit nominees, especially via university email lists. A further limitation of this study was that interviewees were specifically asked how arts engagement makes people feel, possibly causing an information bias towards mental health outcomes.

\section{Conclusion}

If health is more than the absence of disease, pain and sickness and is more about adaptation, understanding and acceptance, then the arts may be more powerful than anything medicine has to offer. ${ }^{1}$ This study expands on current knowledge and brings us closer to the development of a causal health-arts theory. To develop the framework into a theory, future research would need to identify and quantify the strength of the relationship between the arts and each outcome suggested in the framework as well as direct and indirect mechanisms of action. Enablers and barriers to arts engagement should be considered and added to the framework, as well as conditions under which the health-arts relationship does or does not occur. The framework could also be enhanced by identifying additional subthemes and determining if a threshold level of arts engagement (eg, hours per week) is needed before outcomes start to accrue, and once initiated, the manner in which outcomes are produced (eg, slowly, quickly, does this change with time). Future research could also look at how outcomes are influenced by mode of engagement (eg, making vs experiencing art), type of artform (eg, visual arts vs literature) and whether engaging in single or multiple types of artforms differentially affects health outcomes. Overall, this framework should be viewed as a starting point and should provoke conversation, debate and further research. It is expected that in time, the framework will need to be reviewed as we learn more about the relationship between arts engagement and general population health.
Author affiliations

${ }^{1}$ School of Population Health and School of Sport Science, Exercise \& Health (M431), The University of Western Australia, Crawley, Western Australia, Australia

${ }^{2}$ School of Population Health (M431), The University of Western Australia, Crawley, Western Australia, Australia

${ }^{3}$ School of Education, Murdoch University, Murdoch, Western Australia, Australia

${ }^{4}$ School of Sport Science, Exercise \& Health, The University of Western Australia, Crawley, Western Australia, Australia

Acknowledgements The authors would like to acknowledge the panel of experts who reviewed the interview guide and the volunteers involved in pilot testing. We are especially grateful to all participants for taking part in this study and would like to thank the reviewers for their helpful and constructive feedback.

Contributors CD, MK and MR conceived this study which forms part of CD's $\mathrm{PhD}$. CD and MR secured funding. CD collected the data, led the analysis and drafted the paper under supervision from MK, PW and MR. CD, MK, PW and MR contributed to the analysis, critical review and the final version of the paper.

Funding This research was supported by the Western Australian Health Promotion Foundation (Research Starter Grant Number 18918). CD is supported by a Western Australian Health Promotion Foundation Research Training Scholarship (Scholarship number 21356).

Competing interests CD is a member of the editorial board of Disseminate (an online platform for Arts and Health research) and in 2013 evaluated the effectiveness of the Musica Viva Live Performance Plus Program and Princess Margaret Hospital Artist in Residence program.

Ethics approval This study was approved by The University of Western Australia Human Research Ethics Committee (RA/4/1/2490) and conformed to the principles embodied in the Declaration of Helsinki.

Provenance and peer review Not commissioned; externally peer reviewed.

Data sharing statement No additional data are available.

Open Access This is an Open Access article distributed in accordance with the Creative Commons Attribution Non Commercial (CC BY-NC 3.0) license, which permits others to distribute, remix, adapt, build upon this work noncommercially, and license their derivative works on different terms, provided the original work is properly cited and the use is non-commercial. See: http:// creativecommons.org/licenses/by-nc/3.0/

\section{REFERENCES}

1. Smith R. Spend (slightly) less on health and more on the arts. BMJ 2002;325:1432-3

2. Putland C. Lost in translation: the question of evidence linking community-based arts and health promotion. J Health Psychol 2008;13:265-76.

3. Hamilton C, Hinks S, Petticrew M. Arts for health: still searching for the holy grail. J Epidemiol Community Health 2003;57:401-2.

4. Bradford Hill A. The environment and disease: association or causation? Proc $R$ Soc Med 1965;58:295-300.

5. lyengar S, Grantham E, Heeman R, et al. How art works: the National Endowment for the Arts' five-year research agenda, with a system map and measurement model. Washington, DC: National Endowment for the Arts, 2012.

6. McCarthy KF, Ondaatje EH. Gifts of the muse: reframing the debate about the benefits of the arts. Santa Monica, CA: RAND Corporation, 2004

7. Davies CR, Rosenberg M, Knuiman M, et al. Defining arts engagement for population-based health research: art forms, activities and level of engagement. Arts Health 2012;4:203-16.

8. World Health Organisation. Preamble to the Constitution of the World Health Organization as adopted by the International Health Conference, New York, 19-22 June 1946; signed on 22 July 1946 by the representatives of 61 States (Official Records of the World Health Organization, no. 2, p. 100) and entered into force on 7 April 1948, 2003.

9. World Health Organisation. Health impact assessment: the determinants of health. 2013. http://www.who.int/hia/evidence/doh/ en/ (accessed Apr 2013). 
10. Rychetnik L, Hawe P, Waters E, et al. A glossary for evidence based public health. J Epidemiol Community Health 2004;58:538-45.

11. Chlan L. Effectiveness of a music therapy intervention on relaxation and anxiety for patients receiving ventilatory assistance. Heart Lung 1998;27:169-76.

12. Staricoff R. Arts in health: a review of the medical literature. London, England: Arts Council England, 2004.

13. Parr H. Arts and social capital. Ment Health Today 2006;(June):23-5.

14. Kagan C, Sixsmith J, Siddiquee A, et al. Community psychology meets participatory arts: well-being and creativity. HOMINIS, International Conference. Havana, Cuba, 2005.

15. Michalos A, Kahlke P. Arts and the perceived quality of life in British Columbia. Soc Indicators Res 2010;96:1-39.

16. Australia Council for the Arts. More than bums on seats: Australian participation in the arts. Canberra: Australia Council for the Arts, 2010.

17. Goss K. Better Together: the report from the Saguaro seminar on civic engagement in America. Cambridge, MA: Kennedy School of Government, Harvard University, 2001:43-51. http://www. bettertogether.org/bt_report.pdf (accessed 20 Aug 2013).

18. Reeves M. Measuring the economic and social impact of the arts: a review. London, England: Arts Council of England, 2002.

19. Guetzkow J. How the arts impact communities: an introduction to the literature on arts impact studies. Princeton, NJ: Princeton University, 2002.

20. Wilkinson A, Waters A, Bygren LO, et al. Are variations in rates of attending cultural activities associated with population health in the United States? BMC Public Health 2007;7:226.

21. Bygren L, Konlaan B, Johansson S. Attendance at cultural events, reading books or periodicals, and making music or singing in a choir as determinants for survival: Swedish interview survey of living conditions. BMJ 1996;1996:1577-80.

22. Windsor J. Your health and the arts: a study of the association between arts engagement and health. London: Arts Council England, 2005.

23. Madden C, Bloom T. Creativity, health and arts advocacy. Int $J$ Cultur Policy 2004;10:133-56.

24. Wright R, John L, Alaggia R, et al. Community-based arts program for youth in low-income communities: a multi-method evaluation. Child Adolesc Soc Work J 2006;23:635-52.

25. Gasman M, Anderson-Thompkins S. A renaissance on the eastside motivating inner-city youth through art. J Educ Students Placed Risk 2003;8:429-50.

26. South J. Community-based arts for health: a literature review. Leeds Leeds Metropolitan University, 2004.

27. Krieger $\mathrm{N}$. Theories for social epidemiology in the 21st century: an ecosocial perspective. Int J Epidemiol 2001;30:668-77.

28. Engel $\mathrm{G}$. The need for a new medical model: a challenge for biomedicine. Science 1977;196:129-36.

29. Teddlie C, Yu F. Mixed methods sampling: a typology with examples. J Mixed Methods Res 2007;1:77-100.
30. Mason M. Sample size and saturation in PhD studies using qualitative interviews. Forum 2010;11. http://www. qualitative-research.net/index.php/fqs/article/view/1428/3027 (accessed Mar 2012).

31. Australian Bureau of Statistics. 2011 Census QuickStats: Western Australia, 2012. http://www.censusdata.abs.gov.au/ census_services/getproduct/census/2011/quickstat/5 (accessed Apr 2013).

32. Gillham B. Research interviewing: the range of techniques. Maidenhead: McGraw-Hill International, 2005.

33. QSR International. NVivo, 2013. http://www.qsrinternational.com/ products nvivo.aspx (accessed Dec 2013).

34. Welsh E. Dealing with Data: Using NVivo in the Qualitative Data Analysis Process. Forum: Qualitative Social Research, 2002.

35. Braun V, Clarke V. Using thematic analysis in psychology. Qual Res Psychol 2006;3:77-101.

36. QSR International. NVivo 9 advanced: conducting in depth analysis, discover patterns, visualise your data and share your findings. Burlington, MA: QSR International Pty Ltd, 2010.

37. Davies CR, Knuiman M, Pikora T, et al. Health in arts: are arts settings better than sports settings for promoting anti-smoking messages? Perspect Public Health, 2013. http://rsh.sagepub.com/ content/early/2013/10/16/1757913913502475.full.pdf+html (accessed Dec 2013)

38. Mills $\mathrm{C}$, Knuiman M, Rosenberg $\mathrm{M}$, et al. Are the arts an effective setting for promoting health messages? Perspect Public Health 2013;133:116-21.

39. World Health Organisation. Mental health: strengthening our response. 2010. http://www.who.int/mental_health/en/ (accessed Jan 2014).

40. Wright $\mathrm{P}$, Davies $\mathrm{C}$, Haseman B, et al. Arts practice and disconnected youth in Australia: impact and domains of change. Arts Health 2013;5:190-203.

41. White M. Establishing common ground in community-based arts in health. J R Soc Promot Health 2006;126:128.

42. Skowronski J, Betz A, Thompson C, et al. Social memory in everyday life: recall of self-events and other-events. J Pers Soc Psychol 1991;60:831-43.

43. Australian Bureau of Statistics. Attendance at selected cultural venues and events, Australia, 2010-11. Canberra: ABS, 2010.

44. Department of Culture and the Arts. Arts and culture in Western Australia 2009: vital statistics fact sheet. Perth: Department of Culture and the Arts, 2009.

45. Mills C, Rosenberg M, Lovering L, et al. The effectiveness of youth audience participation at dance performances to promote the "Be Active" physical activity message. UNESCO Observatory J Multidiscip Res Arts 2011;2:2.

46. Moynihan R. Too much medicine? BMJ 2002;324:859.

47. Clift S. Creative arts as a public health resource: moving from practice-based research to evidence-based research. Perspect Public Health 2012;132:120-7. 